\title{
POLA TUMPANG SARI KARET-PADI SAWAH PADA TINGKAT PETANI DI LAHAN PASANG SURUT (Studi Kasus Di Desa Nusantara, Kecamatan Air Sugihan, Kabupaten OKI, Provinsi Sumatera Selatan)
}

\author{
Rubber-Rice Intercropping System at Farmer Level in Tidal Swamp (Case Study in Nusantara Village, Air \\ Sugihan, OKI District, South Sumatra Province) \\ Sahuri, Andi Nur Cahyo, dan Iman Satra Nugraha \\ Balai Penelitian Sembawa, Pusat Penelitian Karet \\ J1. Raya Palembang-Betung Km 29. PO BOX: 1127, Palembang 30001, Indonesia \\ Email : sahuri_agr@ymail.com
}

Diterima 6 Desember 2015 / Direvisi 21 April 2016 / Disetujui 2 Mei 2016

\begin{abstract}
Abstrak
Usahatani padi sebagai tanaman sela karet sudah dilakukan oleh petani daerah pasang surut. Dengan adanya pola ini, diharapkan intensitas pemeliharaan karet meningkat sehingga dapat meningkatkan produktivitas lahan, pendapatan petani dan pertumbuhan tanaman karet. Pengkajian dilaksanakan di lahan pasang surut tipe luapan C Air Sugihan, Sumatera Selatan pada bulan Juni dan Oktober 2014. Tujuan pengkajian ini adalah untuk mengetahui pertumbuhan karet, hasil padi dan pendapatan petani pola tumpangsari karet-padi di daerah pasang surut. Hasil pengkajian menunjukkan bahwa pertumbuhan lilit batang karet klon PB 260 umur 3 tahun pola tumpangsari karet-padi dengan sistem bedengan 16,52\% lebih tinggi dibandingkan dengan pertumbuhan lilit batang karet monokultur tanpa sistem bedengan. Produksi padi sebagai tanaman sela karet adalah $2.800 \mathrm{~kg} / \mathrm{ha}$ GKG. Usahatani padi sebagai tanaman sela karet pada saat harga rendah masih menguntungkan dengan $\mathrm{R} / \mathrm{C}$ ratio 1,46 , sedangkan pada saat harga tinggi sangat menguntungkan dengan $\mathrm{R} / \mathrm{C}$ ratio 1,94. Hal ini menunjukkan bahwa usahatani padi sebagai tanaman sela karet di daerah pasang surut secara ekonomis menguntungkan dan layak untuk dikembangkan, terutama pada areal karet rakyat. Pola tumpangsari karet-padi di daerah pasang surut sebaiknya dilakukan dengan sistem bedengan yaitu memberikan air irigasi, membuat tinggi muka air tetap agar lapisan di
\end{abstract}

bawah perakaran tanaman karet dan padi dalam kondisi jenuh air sehingga mampu menekan keracunan pirit $\left(\mathrm{FeS}_{2}\right)$. Selain itu, adanya perbaikan unsur hara serta penggunaan klon karet dan varietas yang adaptif untuk meningkatkan produktivitas tanaman karet dan padi.

Kata kunci : Tanaman sela, padi, karet, tata kelola air

Abstract
Lowland rice farming system had been practised
by farmers at tidal swampy area. This farming
system could be expected of rubber maintenance
intensity increasing, which could be increased of
land productivity, farmer income and rubber plant
growth. The study was conducted in the tidal
swampy area C type of Air Sugihan, South Sumatra
on July and October 2014. The objective of study was
aimed to collected information about the rubber
growth, the rice production and farmers income of
rubber-rice farming system in the tidalswampy area.
The results showed that the girth increment of PB
260 clone at 3 years old on rubber-rice farming sytem
with bed system was $16.52 \%$ higher than the girth of
monoculture system. The rice production as rubber
intercroping was 2.800 kg / ha dry milled rice. The
rice cultivation as rubber intercrop on the low price
time had profitable with the R/C ratio was 1.46 ,
whatever on high price time was 1.94 . Economically
showed that the rice cultivation as rubber intercrop
on tidal swampy area was profitable and reasonable
to be establisment, especially in smallholder rubber
farmer lands. The rubber rice intercroping system on


tidal swampy as well as done with bed system was gived of irrigation water, therefore water table was maintained below rubber root zone and rice was on water logging condition so could be avoided effect of pyrite $\left(\mathrm{Fe} \mathrm{S}_{2}\right)$. Beside that, nutrient improvement and used adaptive of rubber clone and rice variety for of rubber and rice plant increased.

Keywords : Intercrop, lowland rice, rubber, water management

\section{Pendahuluan}

Lahan pasang surut mempunyai potensi untuk pengembangan usahatani karet-padi yang berproduktivitas tinggi bila dilakukan dengan menerapkan teknologi spesifik lokasi dan tata kelola air yang tepat. Menurut (Suyanto et al., 2000), usahatani karet di lahan pasang surut Sumatera Selatan sudah sejak tahun 1920-an. Peningkatan harga karet antara tahun 1910-1920 menyebabkan penanaman karet dan produksi karet rakyat meningkat dari 150 ton pada tahun 1912 menjadi 128 ribu ton pada tahun 1925.

Di Sumatera Selatan luas lahan pasang surut sekitar 1,6 juta ha dan baru sekitar 0,36 juta ha yang digunakan untuk usaha pertanian (Badan Litbang Pertanian, 2011 dan BPS Sumatera Selatan, 2014). Berdasarkan tipe luapannya lahan pasang surut terdiri dari: 1) tipe $\mathrm{A}$, lahan terluapi oleh pasang besar maupun pasang kecil, 2) tipe B, lahan terluapi oleh pasang besar saja, 3) tipe $C$, lahan tidak terluapi oleh air pasang besar maupun pasang kecil, namun permukaan air tanahnya kurang dari $50 \mathrm{~cm}$, dan 4) tipe $\mathrm{D}$, lahan tidak terluapi oleh air pasang besar maupun pasang kecil, namun permukaan air tanahnya lebih dari 50 cm (Widjaja-Adhi et al., 1992). Dalam rentan tahun 2007-2010 terjadi konversi lahan ke perkebunan sekitar 86.552 ha dan ke permukiman sekitar 53.389 ha. Akibatnya kapasitas produksi padi hilang sebesar 0,56 juta ton (Wijaksono dan Navastara, 2012). Selain itu, dalam rentan tahun 2011-2012 produksi padi turun sekitar 3,32\% dan luas panen turun sekitar 1,28\% (BPS Sumatera Selatan, 2014).
Pengelolaan tanah dan air lahan pasang surut dilakukan secara hati-hati, karena lahan pasang surut rapuh (fragile). Kesalahan dalam pengelolaan mengakibatkan pirit $\left(\mathrm{FeS}_{2}\right)$ teroksidasi sehingga lahan menjadi masam ( $\mathrm{pH}$ 1,3 - 3,3) karena menghasilkan ion besi $\left(\mathrm{Fe}^{3+}\right)$, ion sulfat $\left(\mathrm{SO}_{4}^{-2}\right)$ dan melimpahnya ion $\mathrm{H}^{+}$sehingga pertumbuhan tanaman tertekan. Pirit tidak berbahaya bagi tanaman bila berada dalam kondisi tereduksi (Widjaja-Adhi et al., 1992 dan Subagyo, 2006). Tujuan pengelolaan tanah dan air di lahan pasang surut adalah untuk menyediakan kebutuhan evapotranspirasi tanaman, membuang kelebihan air, pencucian (leaching) elemen toksik dan mencegah penurunan muka tanah (Ghulamahdi et al., 2011; dan Ghulamahdi, 2014). Perpaduan pengelolaan tanah dan air diharapkan dapat meningkatkan pertumbuhan dan produksi karet dan padi.

Produksi padi pada lahan tipe luapan A dan B lebih dari 3,5 ton/ha GKG, sedangkan pada lahan tipe luapan $C$ dan $D$ kurang dari 3,5 ton/ha GKG. Hal ini karena pada lahan tipe C dan D kedalaman air tanah dangkal kurang dari $50 \mathrm{~cm}$, banyak lahan rusak dan mengandung racun dari oksidasi pirit $\mathrm{pH}$ tanah dan air rendah, serta intensitas serangan hama dan penyakit tinggi (Sahuri et al., 2014; Rosyid dan Sahuri, 2014). Berdasarkan permasalahan tersebut banyak petani daerah pasang surut tipe luapan $\mathrm{C}$ dan $\mathrm{D}$ beralih ke usahatani karet. Hal ini karena usahatani karet sangat jarang terserang hama dan penyakit, tahan terhadap pirit dan harga jual hasil karet relatif stabil.

Kendala usahatani karet di lahan pasang surut adalah air tanah yang dangkal dan $\mathrm{pH}$ yang ekstrim yang menyebabkan pertumbuhan dan produksi karet tertekan dan dalam kondisi tergenang akan menggugurkan daun. Produksi karet klon RRIM 600 (1.679 $\mathrm{kg} / \mathrm{ha} /$ tahun) dan GT 1 (1.253 kg/ha/tahun) pada lahan sulfat masam, lebih rendah dibandingkan dengan produksi karet RRIM $600(5.038 \mathrm{~kg} / \mathrm{ha} /$ tahun $)$ dan GT 1 (3.758 $\mathrm{kg} / \mathrm{ha} /$ tahun) pada tanah non sulfat masam (Wijaya et al., 2009). Selain itu, perakaran tanaman kurang kuat sehingga cenderung 
tumbuh miring, konsentrasi $\mathrm{O}_{2}$ rendah sehingga absorpsi hara oleh akar rendah, proses pencucian $\mathrm{N}, \mathrm{P}, \mathrm{K}, \mathrm{Mg}, \mathrm{Ca}$, dan S tinggi, dan lapisan kedap air tidak jauh dari permukaan tanah sehingga perkembangan akar tunggang terhambat (Adiwiganda, 1985).

Berdasarkan kondisi di atas maka perlu dilakukan pola tumpangsari karet-padi dengan sistem bedengan, klon karet dan varietas padi yang adaptif untuk meningkatkan produktivitas lahan tersebut. Menurut Sahuri et al. (2014), sistem bedengan adalah penanaman dengan mengatur kedalaman muka air tanah agar kondisi tanah lebih reduktif sehingga dapat menekan oksidasi pirit. Dengan sistem tersebut tanaman karet dan padi dapat dibudidayakan di lahan pasang surut. Kedalaman muka air yang tetap di dalam saluran akan menghilangkan pengaruh dari kelebihan air sehingga tanaman karet dan padi tidak tergenang dan respirasi akar tidak terganggu

Tulisan ini bertujuan untuk mengkaji penerapan pola tumpangsari karet-padi di daerah pasang surut, mengetahui pertumbuhan karet pada pola tumpangsari padi, hasil padi sebagai tanaman sela karet dan pendapatan petani pola tumpangsari karetpadi di daerah pasang surut tipe luapan C. Hasil kajian ini diharapkan dapat dijadikan sebagai salah satu bahan pertimbangan bagi pengembangan pola tumpangsari karet-padi di daerah pasang surut lainnya.

\section{Bahan dan Metode}

\section{Tempat dan Waktu}

Pengkajian dilaksanakan di lahan pasang surut Desa Nusantara, Kecamatan Air Sugihan, Kabupaten Ogan Komering Ilir (OKI), Provinsi Sumatera Selatan. Waktu pelaksanaan penelitian pada bulan Juni dan Oktober 2014. Lokasi kajian terletak pada ketinggian 10 - 11 meter di atas permukaan laut (dpl).

Lokasi pengkajian adalah lahan pasang surut tipe luapan $C$ dengan permukaan air tanah dangkal $<50 \mathrm{~cm}$. Daerah ini termasuk dalam zona II, yaitu pasang surut air tawar sehingga pengaruh langsung air laut sudah tidak ada, tetapi energi pasang surut masih terasa berupa naik turunnya air sungai yang mengikuti siklus gerakan air pasang surut (Widjaja-Adhi et al., 1992; Subagyo, 1996, dan Subagyo, 2006).

\section{Kondisi Petani}

Secara umum petani daerah ini melaksanakan uasahatani yang berorientasi pada kebutuhan pangan keluarga yaitu usahatani padi sawah. Produktivitas padi di lokasi kajian rata-rata $2.800 \mathrm{~kg} / \mathrm{ha}$ GKG dan dapat menghasilkan beras sebesar $1.500 \mathrm{~kg}$. Menurut Royid et al. (2008), hanya dengan mengusahakan 0,5 ha, petani dapat mencukupi kebutuhan pangan keluarga. Namun, untuk diandalkan sebagai usahatani utama tidak akan mampu mencukupi kebutuhan keluarga. Oleh karena itu, perlu ada usahatani karet untuk menambah pendapatan keluarga.

Berkembangnya usahatani padi dan karet, maka petani di daerah ini sudah mulai melakukan pola tumpangsari karet-padi untuk meningkatkan pendapatan keluarga. Pola tanam ini dapat dilakukan sepanjang tanaman karet belum menghasilkan dengan menerapkan pola tanaman yang sesuai dengan musim. Penanaman padi di antara tanaman karet dengan jarak baris padi dari tanaman karet $1 \mathrm{~m}$, maka dalam 1 ha lahan tanaman karet yang dapat dimanfaatkan untuk tanaman sela padi hanya sekitar 0,5 ha. Oleh karena itu, dengan luasan tersebut dapat mencukupi kebutuhan pangan keluarga petani ditambah pendapatan dari usahatani karet. Bahkan dengan kondisi karet yang relatif rendah petani di daerah ini melakukan pola tumpangsari padi di antara tanaman karet belum menghasilkan (TBM) untuk mendukung pendapatan keluarga.

\section{Metode Pengkajian}

Kegiatan pengkajian dilakukan pada lahan petani non kooperator yang dipilih secara 
purposive sampling dengan metode survey. Dasar pemilihan petani tersebut antara lain: sudah mempraktekkan pola tumpang sari karet-padi, memiliki pengalaman cukup lama dibidang usahatani karet dan padi pemilik lahan yang tergabung dalam kelompok tani aktif, dan inovatif, responsif dan apresiatif terhadap teknologi baru.

\section{Cara Pengumpulan Data}

Data primer yang diamati adalah lilit batang karet, analisis tanah sebelum dan sesudah panen padi, analisis air, produksi gabah kering giling (GKG) padi, dan nilai input-ouput padi sebagai tanaman sela karet. Data pertumbuhan lilit batang, analisis tanah dan air diperoleh dari hasil pengamatan lapang secara langsung, sedangkan data produksi padi dan nilai input-output diperoleh dari hasil wawancara langsung pada 5 petani contoh. Pengambilan data produksi padi hanya satu kali musim panen.

Data sekunder berupa curah hujan bulanan diperoleh dari hasil laporan Badan Meteorologi Klimatologi dan Geofisika (BMKG) untuk menentukan pola tanam padi di daerah pasang surut. Petani contoh, pola tanam, dan luas lahan disajikan pada Tabel 1 dan komponen pola usahatani karet-padi ditingkat petani pada lahan pasang surut tipe luapan C disajikan pada Tabel 1.

\section{Pengamatan Tanaman Karet}

Klon karet yang digunakan adalah PB 260 dan varietas padi yang digunakan adalah IR 64. Jarak tanam karet adalah $6 \mathrm{~m} \times 3 \mathrm{~m}$ dan padi dengan sistem tugal menggunakan jarak tanam $20 \mathrm{~cm} \times 25 \mathrm{~cm}$. Sistem bedengan dibuat dengan lebar $200 \mathrm{~cm}$ dan tinggi $50 \mathrm{~cm}$. Pengamatan lilit batang karet dilakukan pada pola tumpangsari karet-padi dan karet monokultur masing-masing 50 tanaman contoh, sehingga jumlah tanaman contoh yang diamati adalah 100 tanaman. Pemilihan tanaman contoh dilakukan secara acak dengan sistem diagonal lahan, sehingga dapat mewakili tanaman karet di lahan tersebut.

\section{Pengamatan Tanah dan Air}

Analisis kimia tanah sebelum dan setelah panen padi dilakukan pada kedalaman $20 \mathrm{~cm}$. Analisis tanah dilakukan untuk $\mathrm{pH}, \mathrm{C}$ organik, $\mathrm{N}, \mathrm{P}_{2} \mathrm{O}_{5}, \mathrm{~K}_{2} \mathrm{O}$, nilai tukar kation $\mathrm{Ca}$, $\mathrm{Mg}$, dan kapasitas tukar kation (KTK). Kemasaman tanah $(\mathrm{pH})$ ditentukan dengan ekstrak 1 : 5 menggunakan $\mathrm{H}_{2} \mathrm{O}$ dan $\mathrm{KCl}$, Corganik ditentukan dengan metode kurmis, $\mathrm{N}$ ditentukan dengan metode Kjedahl, $\mathrm{P}_{2} \mathrm{O}_{5}$ ditentukan dengan metode Bray II, $\mathrm{K}_{2} \mathrm{O}$ ditentukan dengan metode Morgan, Kation dan unsur hara mikro dengan metode Atomic Absorption Spectrometer (AAS), dan KTK dengan metode titrasi.

Analisis kimia air sebelum tanam dilakukan untuk komposisi kemasaman tanah $(\mathrm{pH})$ diukur dengan $\mathrm{pH}$ meter menggunakan elektrode gelas kombinasi. Daya hantar listrik (DHL) diukur dengan menggunakan konduktometer. Kation diukur dengan metode sesuai dengan masing-masing kation. $\mathrm{Ca}, \mathrm{Mg}$, $\mathrm{Fe}, \mathrm{Al}, \mathrm{Mn}$ ditentukan dengan metode AAS. K dan $\mathrm{Na}$ dengan fotometer nyala, $\mathrm{NH}_{4}$ dengan spektrofotometri, $\mathrm{SO}_{4}$ dengan turbidimetri, $\mathrm{Cl}$ dengan argentometri, $\mathrm{PO}_{4}$ dengan kolorimetri pewarnaan biru molibden pada panjang gelombang $693 \mathrm{~nm}, \mathrm{CO}_{3}$ dan $\mathrm{HCO}_{3}$ dengan titrasi menggunakan asam hingga $\mathrm{pH}$ tertentu.

Tabel 1. Petani contoh, pola tanam dan luas lahan pengkajian di lahan pasang surut Air Sugihan Sumatera Selatan.

\begin{tabular}{lccc}
\hline \multicolumn{1}{c}{ Pola tanam } & Jumlah petani & Perlakuan & $\begin{array}{c}\text { Luas lahan } \\
\text { (ha)/petani }\end{array}$ \\
\hline Tumpangsari karet + padi & 3 & Sistem bedengan & 2 \\
Karet monokultur & 2 & Tanpa bedengan & 2 \\
\hline
\end{tabular}




\section{Analisis Data}

Hasil pengamatan lilit batang karet dianalisis dengan uji statistik yaitu uji-t (Gomez and Gomez, 1995) dengan program statistik Minitab 14. Nilai input-output padi sebagai tanaman sela ditampilkan dengan $R / C$ ratio. Menurut Soekartawi (1995), nilai $R / C$ ratio adalah perbandingan antara penerimaan dan biaya, yang secara matematik sebagai berikut:

$$
\mathrm{R} / \mathrm{C}=\mathrm{Po} \cdot \mathrm{Q} /(\mathrm{TFC}+\mathrm{TVC})
$$

\section{Keterangan:}

$\mathrm{R}$ : penerimaan

C : biaya

Po : harga produksi

Q : produksi

TFC : biaya tetap (fixed cost)

TVC : biaya variabel (variable cost)

Dengan keputusan : RC Ratio > 1 , usahatani secara ekonomi menguntungkan, RC Ratio $=1$, usahatani secara ekonomi berada pada titik impas RC Ratio $<1$, usahatani secara ekonomi tidak menguntungkan.

\section{Hasil dan Pembahasan}

\section{Kondisi Iklim}

Lokasi pengkajian mempunyai curah hujan $>2000 \mathrm{~mm} /$ tahun dengan bulan basah (> 200 $\mathrm{mm} /$ bulan) antara 7 - 9 bulan dan bulan kering ( $<100 \mathrm{~mm} /$ bulan) antara $2-3$ bulan. Kondisi tersebut memungkinkan petani menyusun pola tanam yang dapat menutupi tanah sepanjang tahun. Menurut data BMKG Palembang rata-rata curah hujan bulanan tahun 2014 berkisar antara 186,83 mm. Suhu rata-rata sebesar $28,30^{\circ} \mathrm{C}$ dengan suhu minimum $24,5^{\circ} \mathrm{C}$ dan suhu maksimum $33,7^{\circ} \mathrm{C}$. Bulan basah terjadi pada bulan Januari - Mei $(312,20 \mathrm{~mm})$, musim peralihan pada bulan Oktober - Desember $(157,00 \mathrm{~mm})$, dan bulan kering Juni - September $(52,50 \mathrm{~mm})$.

Petani daerah pasang surut mulai mengolah lahan pada bulan Oktober dan menanam padi dengan cara ditebar pada bulan November dan panen padi pada bulan April. Pengolahan lahan untuk palawija (jagung/kedelai) pada bulan Mei dan menanam pada bulan Juni, kemudian panen pada bulan September (Gambar 1). Hal yang perlu dilakukan adalah penanaman tanaman yang tepat pada setiap

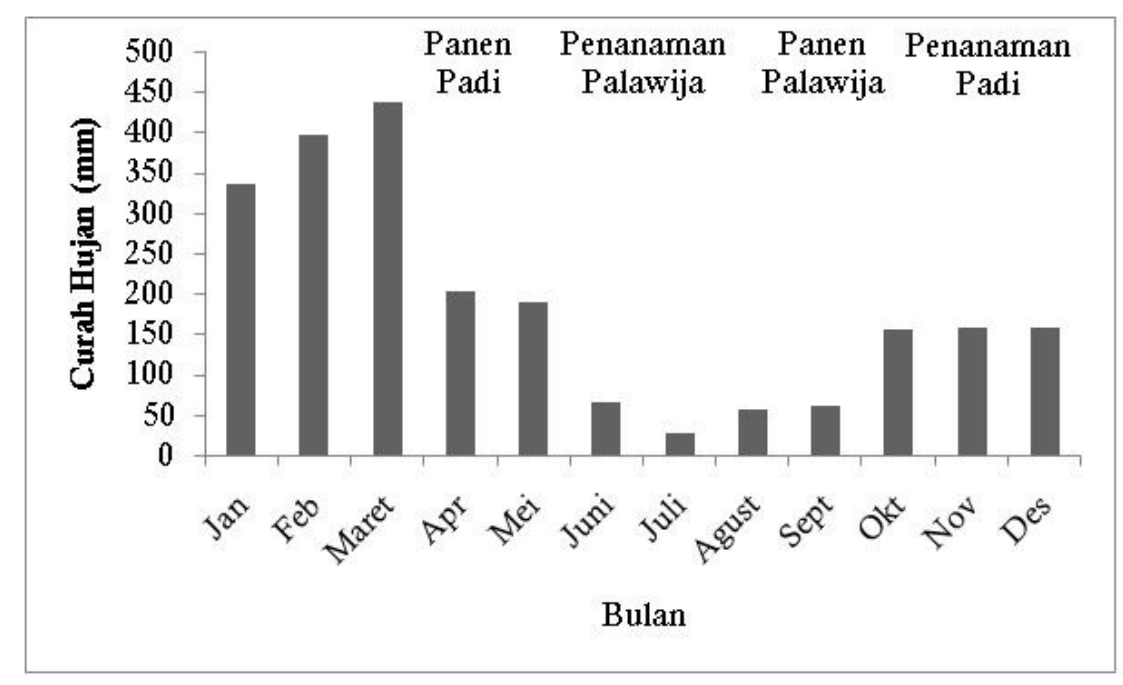

Gambar1. Distribusi curah hujan per bulan di daerah pasang surut Air Sugihan, Badan Meteorologi Klimatologi dan Geofisika, Stasiun Klimatologi Kelas II Kenten Palembang, 2014. 
kondisi musim yang merupakan kunci keberhasilan pola tumpangsari karet-padi di daerah pasang surut.

Menurut Klasifikasi Oldeman et al. (1980) dan As-syakur (2009), lokasi pengkajian termasuk dalam Tipe Iklim B-2, yaitu tipe iklim dengan jumlah bulan basah $(>200$ $\mathrm{mm} /$ bulan) antara 7 - 9 bulan dan jumlah bulan kering ( $<100 \mathrm{~mm} /$ bulan) antara $2-3$ bulan. Dengan demikian daerah tersebut dapat menanam padi dua kali setahun dengan varietas umur pendek dan musim kering yang pendek cukup untuk tanam palawija. Namun, petani daerah pasang surut biasanya hanya menanam padi sekali dalam setahun selanjutnya petani panen ratoon/singgang yaitu anakan padi yang tumbuh kembali setelah dipanen dengan produksi lebih rendah dari panen awal.

\section{Hasil Analisis Tanah}

Hasil analisis tanah sebelum dan sesudah tanam padi sebagai tanaman sela karet menunjukkan kemasaman tanah tinggi, kandungan bahan organik tinggi, kandungan $\mathrm{N}$ sedang, kandungan $\mathrm{P}_{2} \mathrm{O}_{5}$ rendah, kandungan $\mathrm{Ca}$ rendah, kandungan $\mathrm{Mg}$ mulai dari rendah dan KTK sedang. Hasil analisis tanah sebelum dan sesudah pola tumpang sari karet+padi pada areal pengkajian sampai kedalaman $100 \mathrm{~cm}$ belum terdapat lapisan pirit dan tingkat kesuburan tanah cenderung meningkat (Tabel 1). Oleh karena itu, lahan tersebut tidak menimbulkan masalah bagi usahatani karet-padi dengan adanya perlakuan sistem bedengan dan perbaikan kondisi hara dengan pemupukan dan pengapuran serta pengembalian sisa-sisa panen dari tanaman sela padi.

\section{Hasil Analisis Air}

Sistem pengelolaan air usahatani karet-padi pada lokasi kajian dilakukan dengan sistem buka tutup pintu air, yaitu air masuk melalui sistem saluran pemasukan (inlet) dan keluar melalui sistem saluran pengeluaran (outlet) sehingga berpengaruh terhadap tata air mikro di lahan. Menurut Widjaja-Adhi et al. (1997) pengelolaan air di tingkat petani pada lahan pasang surut yang bertipe luapan $\mathrm{C}$ dilakukan dengan sistem aliran satu arah, yaitu saluran tersier dijadikan saluran pemasukan irigasi dan saluran kuarter dijadikan saluran pembuangan menuju saluran tersier drainase. Air di saluran tersier dibuang ketika air surut dan ditutup ketika air pasang besar. Subagyo (2006) menambahkan pengelolaan lahan dan air pada lahan pasang surut tipe luapan $C$ harus hati-hati, karena kesalahan dalam mengatur tata air di saluran tersier akan menyebabkan kegagalan panen karena air tidak sampai ke lahan. Dengan adanya tata air

Tabel 1. Hasil analisis tanah daerah tabukan di daerah pasang surut pada tipe luapan $\mathrm{C}$ di daerah Air Sugihan Tahun 2014

\begin{tabular}{llll}
\hline Peubah analisis & Sebelum & Sesudah & Kriteria \\
\hline a. $\mathrm{pH} \mathrm{H} \mathrm{H}_{2} \mathrm{O}$ & 3,70 & 4,20 & Sangat \\
b. $\mathrm{pH} \mathrm{KCl}$ & 3,50 & 3,80 & Masam \\
Bahan Organik & & & \\
a. $\mathrm{C}(\%)$ & 7,02 & 7,39 & Tinggi \\
b. $\mathrm{N}(\%)$ & 0,33 & 0,54 & Sedang \\
c. $\mathrm{C} / \mathrm{N}(\%)$ & 21,27 & 13,68 & Tinggi \\
a. $\mathrm{P}_{2} \mathrm{O}_{5}($ Bray I) (ppm) & 4,00 & 4,90 & Rendah \\
b. $\mathrm{K}_{2} \mathrm{O}(\mathrm{Morgan})$ & 0,36 & 0,39 & Rendah \\
c. $\mathrm{Ca}(\mathrm{me} / 100 \mathrm{~g})$ & $0,34 \mathrm{~g}$ & 2,31 & Rendah \\
d.Mg (me/100g) & $0,65 \mathrm{~g}$ & 0,63 & Rendah \\
e. $\mathrm{KTK}(\mathrm{me} / 100 \mathrm{~g})$ & 30,00 & 47,26 & Sedang \\
\hline
\end{tabular}

Sumber: data primer diolah, 2014 
mikro di lahan akan terhindar dari keracunan besi dan unsur-unsur racun lainya seperti asam-asam organik.

Sumber air untuk usahatani karet-padi pada lokasi pengkajian adalah dengan memanfaatkan air yang berada di saluran drainase yang dipengaruhi pasang surut air laut. Hal ini berpengaruh pada kandungan kation dan anion yang rendah dalam air dan didominasi oleh $\mathrm{Na}$ dan $\mathrm{Cl}$, namun daya hantar listrik masih rendah $0,49 \mathrm{mmhos} / \mathrm{cm}$ sehingga dapat mengairi dan tidak merusak tanaman karet dan padi. Air ini juga memiliki kemasaman yang tinggi dengan $\mathrm{pH} 4,4$ dan $\mathrm{SO}_{4}^{-2}$ yang tinggi, namun tidak menekan pertumbuhan tanaman karet dan produksi padi sebagai tanaman sela karena adanya sistem bedengan (Tabel 2). Menurut Sunarto (2001), daya hantar listrik 2-4 mmhos/cm masih tergolong salinitas rendah dan tanaman mulai berkurang hasilnya pada tekanan osmose $7 \mathrm{mmhos} / \mathrm{cm}$.

Tabel 2. Data analisis air pada tipe luapan C di daerah Air Sugihan Tahun 2014

\begin{tabular}{lll}
\hline \multicolumn{1}{c}{ Peubah Analisi } & \multicolumn{1}{c}{ Hasil Analisis } & \multicolumn{1}{c}{ Kriteria } \\
\hline $\mathrm{DHL}$ & $0,49 \mathrm{mmhos} / \mathrm{cm}$ & Rendah \\
$\mathrm{Ph}$ & 4,4 & Sangat masam \\
Kation (mg/1 air bebas lumpur) & & \\
a. $\mathrm{NH}_{4}$ & a. 0,81 & Rendah \\
b. $\mathrm{Ca}$ & b. 11,65 & Tinggi \\
c. $\mathrm{Mg}$ & c. 4,87 & Sedang \\
d. $\mathrm{Na}$ & d. 19,63 & Tinggi \\
e. $\mathrm{Fe}$ & e. 0,19 & Rendah \\
f. $\mathrm{Mn}$ & f. 0,00 & Rendah \\
g. $\mathrm{Cu}$ & g. 0,03 & Rendah \\
$\mathrm{Anion}(\mathrm{mg} / 1$ air bebas lumpur) & & \\
a. $\mathrm{PO}_{4}{ }^{2-}$ & a. 0,56 & Rendah \\
b. $\mathrm{SO}_{4}{ }^{2-}$ & b. 111 & Tinggi \\
c. $\mathrm{Cl}^{-}$ & c. 2,69 & Sedang \\
d. $\mathrm{HCO}_{3}^{-}$ & d. 0,32 & Rendah \\
\hline
\end{tabular}

Sumber : data primer diolah, 2014

\section{Penerapan Teknologi Tumpangsari Karet- Padi Petani di Lahan Pasang Surut}

Pengolahan tanah di lahan pasang surut bertujuan memperbaiki kondisi lahan menjadi lebih merata, mempercepat proses pencucian bahan beracun dan mempercepat pencampuran bahan ameliorasi dan pupuk dengan tanah. Menurut Suriadikarta (2005); Suriadikarta dan Sutriadi, (2007), walaupun pengolahan tanah diperlukan tapi tidak harus dilakukan setiap musim, karena pengolahan tanah yang dilakukan selang dua musim tanam tidak menurunkan hasil tanaman. Komponen teknologi budidaya pola tumpangsari karet- padi disajikan pada Tabel 3 dan tata letak pola tumpangsari karet-padi disajikan pada Gambar 2.

Pengolahan tanah di lahan pasang surut tergantung kondisi lahannya. Pengolahan tanah dapat dilakukan dengan bajak singkal kemudian penggemburan atau pelumpuran dikombinasikan dengan herbisida. Bila tanahnya sudah gembur dan merata, maka dilakukan pengolahan tanah minimum dikombinasikan dengan herbisida.

Penanaman padi pada bulan OktoberNovember (awal musim hujan). Hal ini karena pada saat air pasang kondisi tanaman sudah pada fase vegetatif sehingga benih padi yang 
Tabel 3. Komponen teknologi budidaya pola tumpangsari karet-padi

\begin{tabular}{|c|c|c|}
\hline \multirow{2}{*}{ Komponen } & \multicolumn{2}{|c|}{$\begin{array}{lr}\text { Pola Usahatani } \\
\end{array}$} \\
\hline & Tumpangsari Karet-Padi & Karet Monokultur \\
\hline $\begin{array}{l}\text { Pola tanam dan penataan } \\
\text { lahan }\end{array}$ & $\begin{array}{l}\text { Sesuai dengan tipologi lahan } \\
\text { pasang surut tipe luapan C }\end{array}$ & $\begin{array}{l}\text { Tidak sesuai dengan tipologi } \\
\text { lahan pasang surut tipe luapan C }\end{array}$ \\
\hline Pengelolaan tata air mikro & $\begin{array}{l}\text { Saluran kemalir, kuarter dan } \\
\text { tersier. Dibuat sistem bedengan } \\
\text { lebar } 200 \mathrm{~cm} \text { dan tinggi } 50 \mathrm{~cm} \text {. }\end{array}$ & $\begin{array}{l}\text { Tidak ada saluran kemalir, } \\
\text { kuarter dan tersier }\end{array}$ \\
\hline Pengolahan tanah & $\begin{array}{l}\text { Lahan sawah disemprot herbisida } \\
\text { dengan dosis } 41 / \text { ha. } \\
\text { Olah tanah sederhana (minimum } \\
\text { tillage) dengan traktor tangan dan } \\
\text { dilanjutkan pengolahan tanah } \\
\text { menggunakan rotari atau glebeg. } \\
\text { Dibuat bedengan selebar } 2 \mathrm{~m} \text { dan } \\
\text { tinggi } 50-100 \mathrm{~cm} \text { memanjang } \\
\text { untuk barisan tanaman. }\end{array}$ & $\begin{array}{l}\text { Lahan sawah disemprot herbisida } \\
\text { dengan dosis } 41 / \text { ha. } \\
\text { Olah tanah sederhana (minimum } \\
\text { tillage) dengan traktor tangan dan } \\
\text { dilanjutkan pengolahan tanah } \\
\text { menggunakan rotari atau glebeg. }\end{array}$ \\
\hline Penanaman & $\begin{array}{l}\text { Padi ditanam benih langsung } \\
\text { dengan sistem tugal jarak tanam } \\
20 \mathrm{~cm} \times 25 \mathrm{~cm} \text {. Karet ditanam } \\
\text { dengan jarak tanam } 6 \mathrm{~m} \times 3 \mathrm{~m} \\
\text { dan lubang tanam } 40 \mathrm{~cm} \times 40 \mathrm{~cm} \\
\text { x } 40 \mathrm{~cm} .\end{array}$ & $\begin{array}{l}\text { Karet ditanam dengan lubang } \\
\text { tanam } 40 \mathrm{~cm} \text { x } 40 \mathrm{~cm} \times 40 \mathrm{~cm} .\end{array}$ \\
\hline Klon dan Varietas Padi & PB 260 dan IR 64 & PB 260 \\
\hline $\begin{array}{l}\text { Pemupukan dan Ameliorasi } \\
(\mathrm{kg} / \mathrm{ha})\end{array}$ & $\begin{array}{l}\text { Pemupukan } 2 \text { kali/tahun } \\
\text { bersamaan dengan padi, } 200 \\
\mathrm{~kg} / \mathrm{ha} \text { Urea, } 100 \mathrm{~kg} / \mathrm{ha} \text { TSP, } 100 \\
\mathrm{~kg} / \mathrm{ha} \text { Phonska, } 1000 \mathrm{~kg} / \mathrm{ha} \\
\text { Dolomit }\end{array}$ & Tidak ada \\
\hline Pemeliharaan & $\begin{array}{l}\text { Manual dan penggunaan } \\
\text { herbisida }\end{array}$ & $\begin{array}{l}\text { Manual dan penggunaan } \\
\text { herbisida }\end{array}$ \\
\hline Pengendalian hama/penyakit & $\begin{array}{l}\text { Pengendalian hama secara } \\
\text { kimiawi }\end{array}$ & $\begin{array}{l}\text { Pengendalian hama secara } \\
\text { kimiawi }\end{array}$ \\
\hline Panen dan pascapanen padi & $\begin{array}{l}\text { Secara manual dan pengeringan } \\
\text { dengan matahari menggunakan } \\
\text { alas terpal jemur }\end{array}$ & Tidak \\
\hline
\end{tabular}

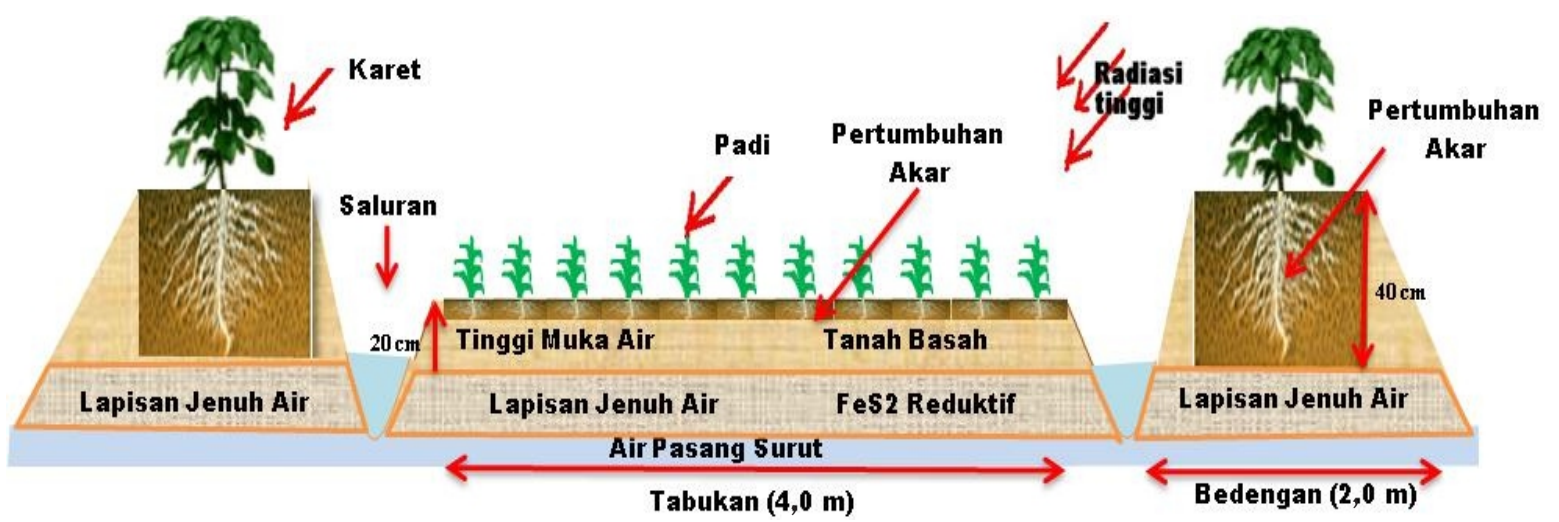

Gambar 2. Sistem pola tumpangsari karet-padi di lahan pasang surut dengan sistem bedengan 
sudah ditebar tidak tergenang. Secara umum petani menanam padi dengan cara ditebar tanpa pengaturan jarak tanam sehingga membutuhkan benih lebih banyak 60 - 80 $\mathrm{kg} / \mathrm{ha}$. Penanaman menggunakan jarak tanam membutuhkan tenaga manusia jauh lebih banyak yang bagi petani merupakan faktor pembatas walaupun membutukan benih hanya $40 \mathrm{~kg} / \mathrm{ha}$.

Pola tumpangsari karet-padi dengan sistem bedengan akan terbentuk daerah tabukan. Pada bedengan (tanah bagian atas yang kering) ditanami karet dan pada tabukan (tanah bagian bawah yang basah) ditanami padi. Tinggi bedengan $1 \mathrm{~m}$, lebar bedengan $2 \mathrm{~m}$, jarak antara bedengan $4 \mathrm{~m}$ dan lebar tabukan adalah $4 \mathrm{~m}$. Pada daerah tabukan dibuat saluran irigasi lebar $25 \mathrm{~cm}$ dan dalam $20 \mathrm{~cm}$ untuk memperlancar pencucian sehingga lahan terhindar dari keracunan besi, pirit dan asam-asam organik.

Pola tumpangsari karet-padi pada tingkat petani dilakukan dengan penataan lahan yang sesuai dengan tipologi tipe luapan C. Lahan sulfat masam akan lebih murah dan aman bila ditata sebagai sawah dengan sistem bedengan (Gambar 3a). Hal ini karena sistem bedengan dapat menciptakan lapisan jenuh air pada daerah perakaran tanaman karet dan padi, tetapi tidak tergenang. Kondisi tersebut akan menghilangkan pengaruh negatif dari kelebihan air pada daerah bedengan yang ditanami karet dan menjaga kondisi reduktif pada daerah tabukan yang ditanami padi.

Pola tanam karet monokultur pada musim hujan tanpa adanya sistem bedengan dan perbaikan saluran drainase menyebabkan tata air buruk sehingga areal tanaman karet menjadi tergenang. Kondisi tersebut dapat merusak sistem perakaran tanaman karet akibatnya oksigen dan akumulasi $\mathrm{CO}_{2}$ di daerah perakaran berkurang, daun menguning, batang mengecil, produksi menurun dan pengaruh lanjut akar tanaman karet membusuk dan tanaman mati (Gambar 3b). Menurut Firmansyah et al. (2012), pembuatan saluran drainase dan tukungan sekitar $50-100 \%$ dari ketinggian genangan air sudah cukup untuk mempertahankan pertumbuhan karet.

Lahan pasang surut untuk usahatani karet dan padi umumnya memiliki kelas kesesuaian lahan S2 dan S3 yang relatif rendah unsur hara. Berbeda dengan lahan kering yang umumnya memiliki kelas kesesuaian lahan S1 yang relatif subur. Namun demikian dengan

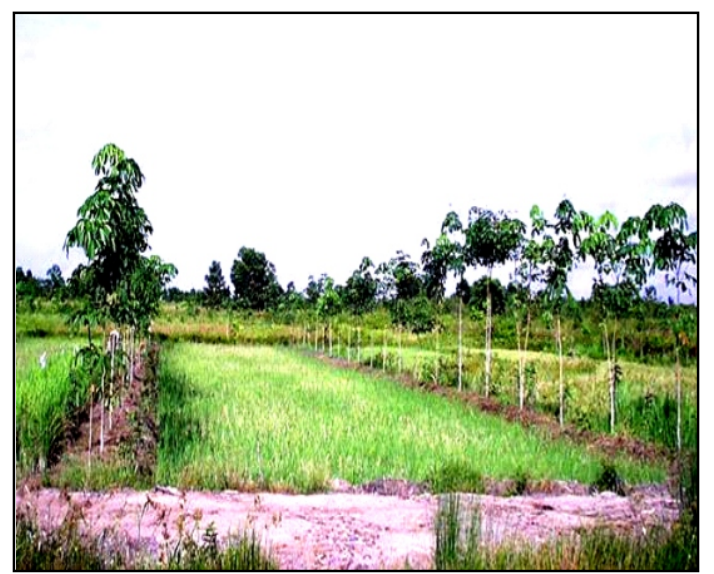

a. Tumpangsari karet + padi

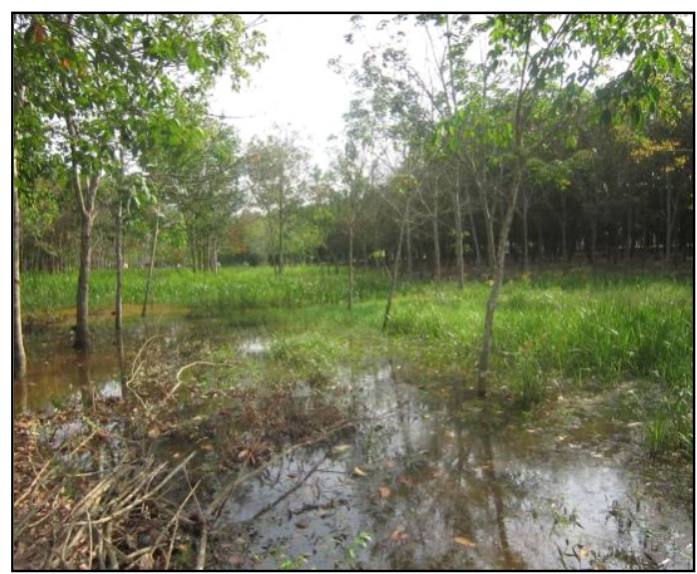

b. Karet monokultur

Gambar 3. Pertumbuhan tanaman karet pola tumpangsari karet-padi dan karet monokultur di daerah pasang surut Air Sugihan, Sumatera Selatan 
pengelolaan saluran drainase dan sistem tanam yang tepat, maka lahan rawa pasang surut dapat dikembangkan untuk tanaman karet dan padi. Menurut Wijaya dan Hidayati (2003) dan Firmansyah (2012), pengelolaan yang minimalis (satu kali cangkul) sudah cukup memadai untuk perbaikan kualitas lahan dan kondisi kelebihan air. Hal tersebut telah mampu meningkatkan kelas kesesuaian lahan dari tidak sesuai (N1) menjadi sesuai marjinal (S3), dan sesuai marjinal (S3) menjadi cukup sesuai (S2). Nilai $\mathrm{pH}$ yang rendah dapat diatasi dengan pemberian pupuk dolomit yang mengandung $\mathrm{Ca}$ dan $\mathrm{Mg}$ secara rutin. Pemberian dolomit sebanyak 2,5 ton/ha sudah cukup memadai untuk meningkatkan hasil karet.

\section{Pertumbuhan Tanaman Karet}

Petani daerah pasang surut, baik di Sumatera Selatan maupun di Kalimantan Tengah umumnya menanam karet menggunakan sistem bedengan. Sistem tanam ini bertujuan menjauhkan perakaran karet dari permukaan air tanah, agar perakaran dapat tumbuh dan berkembang baik sehingga tidak roboh (Rosyid et al., 2008 dan Rosyid et al., 2009).

Hasil pengkajian menunjukkan bahwa pertumbuhan lilit batang karet klon PB 260 umur 3 tahun pada tingkat petani di lahan pasang surut pola tumpangsari karet-padi dengan sistem bedengan 16,52\% lebih tinggi dibandingkan dengan pertumbuhan lilit batang karet monokultur tanpa sistem bedengan (Tabel 4). Hal ini karena dipengaruhi oleh beberapa faktor, yaitu: 1) adanya pengelolaan tata air mikro melalui sistem bedengan pada lahan, 2) adanya pemberian dolomit dan pupuk bersamaan dengan padi untuk memperbaiki kondisi tanah, dan 3) adanya pembuatan saluran irigasi pada daerah tabukan untuk mempercepat proses pencucian bahan beracun.

Pertumbuhan lilit batang karet di lahan pasang surut tanpa adanya sistem bedengan terhambat. Hal ini karena pada saat musim hujan dan pasang besar tanpa adanya sistem bedengan menyebabkan tata air buruk sehingga tanaman karet tergenang. Tanaman karet umumnya tidak toleran tergenang karena secara fisiologis akar karet tidak mempunyai akar nafas, sehingga pada kondisi tergenang akar tanaman tidak dapat bernafas dengan baik. Oleh karena itu, perbaikan sifat fisik dan drainase diperlukan agar tanaman karet tumbuh dengan baik. Lahan pasang surut dapat digunakan untuk budidaya karet, apabila masalah drainase dapat dibenahi, termasuk menurunkan permukaan air tanah.

Pengembangan karet di lahan pasang surut dengan teknologi bedengan menunjukkan klon unggul PB 260 dan IRR 39 mampu hidup saat tanam, sedangkan jika tidak menggunakan bedengan kebanyakan pertumbuhan karet terhambat dan mati. Pembuatan tukungan $50 \%$ dari ketinggian genangan air sudah cukup untuk mempertahankan pertumbuhan karet klon $\mathrm{PB}$ 260, sedangkan untuk klon IRR 39 yang terbaik jika tinggi tukungan $100 \%$ dari genangan (Firmansyah et al., 2012). Pertumbuhan lilit batang tanaman karet dilahan pasang surut tanpa menggunakan teknologi bedengan mengalami penurunan sekitar $20 \%$ dibandingkan dengan

Tabel 4. Pertumbuhan lilit batang karet klon PB 260 umur 3 tahun pada tingkat petani dengan dan tanpa pola tanam tumpang sari karet-padi di lahan pasang surut Air Sugihan, Sumatera Selatan

\begin{tabular}{lcc}
\hline \multicolumn{1}{c}{ Perlakuan } & Lilit batang $(\mathrm{cm})$ & Signifikasi (P) \\
\hline Tumpang sari karet + padi (Sistem Bedengan) & $26,17^{*}$ & \multirow{2}{*}{0,001} \\
Karet monokultur (Tanpa Bedengan) & $22,46^{*}$ & \\
\hline
\end{tabular}

Sumber : Data primer diolah, 2014

Keterangan : ${ }^{*}=$ Hasil uji t-student berbeda nyata pada taraf $5 \%$ 
pertumbuhan lilit batang tanaman karet dengan bedengan (Wijaya et al., 2014). Pertumbuhan lilit batang klon PB 260 umur 3 tahun pada pengujian klon karet di daerah pasang surut Air Sugihan Sumatera Selatan sekitar 29,36 cm (Rosyid et al., 2009).

\section{Nilai Tambah Pola Tumpangsari Karet - Padi}

Nilai tambah pola tumpangsari karet-padi adalah meningkatkan produktivitas lahan di antara tanaman karet muda, meningkatkan pendapatan petani, mengurangi tingkat serangan hama dan penyakit serta tanaman karet terpelihara. Produksi padi sebagai tanaman sela karet di daerah pasang surut tipe luapan $\mathrm{C}$ adalah 2,8 ton/ha GKG. Produksi tersebut masih lebih rendah dibandingkan dengan produksi padi pada daerah pasang surut tipe luapan $\mathrm{A}$ dan $\mathrm{B}$ ( $>3,5$ ton/ha) GKG. Hal ini karena pada lahan tipe luapan $C$ memilki kedalaman air tanah dangkal $<50 \mathrm{~cm}$, $\mathrm{pH}$ tanah dan air yang rendah karena oksidasi pirit, dan tingginya intensitas serangan hama dan penyakit. Suastika dan Sutriadi (2001), menambahkan bahwa rendahnya produktivitas tanaman di lahan pasang surut disebabkan oleh kemasaman tanah yang tinggi sehingga kelarutan $\mathrm{Fe}, \mathrm{Al}$, dan $\mathrm{Mn}$ menjadi tinggi, serta rendahnya ketersediaan $\mathrm{P}$ dan $\mathrm{K}$. Oleh karena itu, pemanfaatan lahan rawa secara berkelanjutan, diperlukan sistem bedengan dengan memberikan air irigasi dan membuat tinggi muka air tetap di dalam saluran.

Usahatani padi per hektar sebagai tanaman sela karet pada tahun pertama pada saat harga jual tinggi $\mathrm{Rp} 4.650 / \mathrm{kg}$ GKG, maka mendapatkan penerimaan sebesar $\mathrm{Rp}$ 13.020.000,-, keuntungan sebesar $\mathrm{Rp}$ 6.313.162,- $(\mathrm{R} / \mathrm{C}$ ratio 1,94$)$ per satu musim dengan biaya pengeluaran sebesar $\mathrm{Rp}$

Tabel5. Analisis usaha tani padi per hektar pada tahun pertama sebagai tanaman sela karet di lahan pasang surut Air Sugihan, Sumatera Selatan, musim hujan (MH) 2014

\begin{tabular}{|c|c|c|c|c|}
\hline Uraian & Jumlah & Satuan & Harga (Rp) & Total (Rp) \\
\hline \multicolumn{5}{|l|}{ Biaya produksi } \\
\hline Benih padi IR 64 & 80 & $\mathrm{~kg}$ & 6.000 & 480.000 \\
\hline Urea & 200 & $\mathrm{~kg}$ & 2.200 & 440.000 \\
\hline TSP & 100 & $\mathrm{~kg}$ & 2.200 & 220.000 \\
\hline Phonska & 100 & $\mathrm{~kg}$ & 2.800 & 280.000 \\
\hline Dolomit & 1000 & $\mathrm{~kg}$ & 600 & 600.000 \\
\hline Herbisida & 8 & liter & 45.000 & 360.000 \\
\hline Total biaya produksi & & & & 2.380 .000 \\
\hline \multicolumn{5}{|l|}{ Tenaga kerja } \\
\hline Penyemprotan gulma sebelum tanam & 2 & HOK & 46.059 & 92.118 \\
\hline Bajak dengan traktor & 1 & Unit & 550.000 & 550.000 \\
\hline Pembuatan bedengan dan tabukan & 60 & HOK & 46.059 & 2.763 .540 \\
\hline Penanaman padi secara tebar & 2 & HOK & 46.059 & 92.118 \\
\hline Pemupukan 3 kali (Karet dan Padi) & 6 & HOK & 46.059 & 276.354 \\
\hline Penyemprotan gulma setelah tanam & 2 & HOK & 46.059 & 92.118 \\
\hline Panen dan pasca panen padi & 10 & HOK & 46.059 & 460.590 \\
\hline Total biaya dan upah & & & & 4.326 .838 \\
\hline Total Pengeluaran & & & & 6.706 .838 \\
\hline Hasil bersih padi GKG (kg/ha) & 2.800 & & & \\
\hline Harga jual (Rp/kg) & 4.650 & 3.500 & & \\
\hline Penerimaan $(\mathrm{Rp})$ & 13.020 .000 & 9.800 .000 & & \\
\hline Pendapatan (Rp) & 6.313 .162 & 3.093 .162 & & \\
\hline $\mathrm{R} / \mathrm{C}$ ratio & 1,94 & 1,46 & & \\
\hline
\end{tabular}

Sumber: data primer diolah, 2014 yang disesuaikan dengan harga wilayah pengkajian 
6.706.838,-. Usahatani padi sebagai tanaman sela karet pada saat harga jual rendah $\mathrm{Rp}$ $3.500 / \mathrm{kg}$ GKG, maka mendapatkan penerimaan sebesar Rp 9.800.000,-, keuntungan sebesar $\mathrm{Rp}$ 3.093.162,- (R/C ratio $1,46)$ per satu musim dengan biaya pengeluaran sebesar Rp 6.706.838,. Hal ini menunjukkan bahwa usahatani padi sebagai tanaman sela karet secara ekonomis menguntungkan dan layak untuk dikembangkan karena memiliki nilai $\mathrm{R} / \mathrm{C}$ lebih dari 1 pada saat harga gabah rendah dan tinggi. Analisis usahatani padi dapat dilihat pada Tabel 5 .

\section{Kesimpulan}

Teknologi pola tumpangsari karet-padi dengan sistem bedengan telah diterapkan oleh petani di daerah pasang surut. Pertumbuhan lilit batang karet klon PB 260 umur 3 tahun pola tumpangsari karet-padi dengan sistem bedengan dapat mencapai 16,52\% lebih tinggi dibandingkan dengan pertumbuhan lilit batang karet monokultur tanpa sistem bedengan. Produksi padi sebagai tanaman sela karet dapat mencapai 2,80 ton/ha GKG dan masih menguntungkan pada saat harga gabah rendah dengan $\mathrm{R} / \mathrm{C}$ ratio 1,46 . Usahatani padi sebagai tanaman sela karet di daerah pasang surut secara ekonomis menguntungkan dan layak untuk dikembangkan menggunakan pengelolaan lahan dengan sistem bedengan, menggunakan klon karet dan varietas padi adaptif.

\section{Ucapan Terima Kasih}

Ucapan terima kasih disampaikan kepada Gapoktan Desa Air Sugihan, Kabupaten OKI, Sumatera Selatan yang telah membantu terlaksananya penelitian ini.

\section{Daftar Pustaka}

Adiwiganda, Y.T. (1985). Sistem drainase tanah di perkebunan karet. Warta Perkaretan, 4(1), 15-18.
As-syakur, A.R. (2009). Evaluasi zona agroklimat dari klasifikasi schimidtferguson menggunakan aplikasi sistem informasi geografi (SIG). Jurnal Pengkajian Ilmu dan Pengajaran Matematika dan Ilmu Pengetahuan Alam, 3(1), 17-22.

Badan Litbang Pertanian. (2011, November 2014). Inovasi pertanian Sumatera Selatan mendukung swasembada beras nasional. Edisi 17-23 Agustus 2011. No. 3419 Tahun XLI. Diakses dari www.litbang.pertanian.go.id

Badan Pusat Statistik. (2014). Sumatera Selatan dalam angka: luas lahan menurut jenis lahan di Provinsi Sumatera Selatan 2011-2013. Palembang : Badan Pusat Statistik Provinsi Sumatera Selatan.

Firmansyah, M.A., Yuliani, N., Nugroho, W.A., dan Bhermana, A. (2012). Kesesuaian lahan rawa pasang surut untuk tanaman karet di Tiga Desa Eks lahan sejuta hektar, Kabupaten Pulang Pisau, Provinsi Kalimantan Tengah. Jurnal Lahan Suboptimal, 1(2), 149-157.

Ghulamahdi, M., Melati, M., Aziz, S.A., Junaedi, A., Sahuri, Puspitasari, Y., dan Sagala, D. (2011). Agronomical performances of soybean cultivated under saturated soil culture on tidal swamps. Proceedings The 7th Asian Crop Science Association Confrence, Improving food, energy and environment with better crops, Bogor, September 2011.

Ghulamahdi, M. (2014). Budidaya kedelai produksi tinggi di lahan pasang surut : Tantangan Aplikasi dalam Skala Luas. Seminar Nasional Hari Kebangkitan Teknologi Nasional Ke-19 Tahun 2014 Inovasi Pangan, Enersi Dan Air Untuk Daya Saing Bangsa, Bogor, Agustus 2014.

Gomez, K.A and Gomez, A.A. (1995). Statistical Procedures for Agricultural Research. Jakarta: Universitas Indonesia Press.

Oldeman. L., Irsal, R. dan Muljadi, L. (1980). Agro-climatic map of Sumatra. Bogor: IPB Press. 
Rosyid, M.J., Wijaya, T., dan Boerhendhy, I. (2008). Usahatani karet di daerah pasang surut Sumatera Selatan dan Kalimantan Tengah. Prosiding Lokakarya Nasional Agribisnis Karet, Yogyakarta, Agustus 2008.

Rosyid, M.J., Wijaya, T, dan Boerhendhy, I. (2009). Pengujian penggunaan bahan tanam dan adaptabilitas berbagai klon pada lahan pasang surut tipe luapan $\mathrm{D}$ di Sumatera Selatan. Prosiding Lokakarya Nasional Pemuliaan Tanaman Karet, Batam, Agustus 2009.

Rosyid, M.J dan Sahuri. (2014). Budidaya karet pada lahan pasang surut di Sumatera Selatan. Prosiding Seminar Nasional Lahan Suboptimal, Palembang, September 2014.

Sahuri, Stevanus, C.T., dan Rosyid, M.J. (2014). Potensi pemanfaatan lahan dan perbaikan kultur teknis lahan rawa pasang surut untuk tanaman karet di Desa Riding, Kabupaten Ogan Komering Ilir, Sumatera Selatan. Prosiding Seminar Nasional Lahan Suboptimal, Palembang, September 2014.

Suastika, I.W. dan Sutriadi, M.T. (2001). Pengaruh perbaikan tata air mikro terhadap kualitas air tanah dan hasil tanaman. Prosiding Seminar Hasil Penelitian Pengembangan Sistem Usaha Pertanian Lahan Pasang Surut Sumatera Selatan, Bogor, Juni 2001.

Subagyo, H. (1996). Potensi pengembangan dan tata ruang lahan rawa untuk pertanian. Prosiding Simposium Nasional dan Kongres VI PERAGI, Jakarta, Juni 1996.

Subagyo, H. (2006). Klasifikasi dan penyebaran lahan rawa. Dalam Suriadikarta, D.A., Kurnia, U., Mamat H.S., Hartatik, W., dan Setyorini, D. (Eds). Karakteristik dan Pengelolaan Lahan Rawa (pp 1-22). Bogor : Balai Besar Penelitian dan Pengembangan Sumberdaya Lahan Pertanian.
Soekartawi. (1995). Analisis Usahatani. Jakarta: Universitas Indonesia Press.

Sunarto. (2001). Toleransi kedelai terhadap tanah salin. Buletin Agronomi , 29(1), 2730.

Suriadikarta, D.A. (2005). Pengelolaan lahan sulfat masam untuk usaha pertanian. Jurnal Penelitian dan Pengembangan Pertanian, 24(1), 36-45.

Suriadikarta, D.A. dan Sutriadi, M.T. (2007). Jenis-jenis lahan berpotensi untuk pengembangan pertanian di lahan rawa. Jurnal Penelitian dan Pengembangan Pertanian, 26(3), 115-122.

Suyanto, S., Permana, R.P., and Khususiyah, N. (2000). Fire, livelihood and swamp management evidence from Southern Sumatra International Centre for Research in Agroforestry Southeast Asia Regional Research Programme. $\mathrm{D}$ i a $\mathrm{k} \mathrm{s}$ e s d a $\mathrm{r}$ i http://webcache.googleusercontent.com

Wijaksono, R. R. dan Navastara, A.M. (2012). Pengendalian perubahan pemanfaatan lahan pertanian tanaman pangan di Kabupaten Banyuasin, Provinsi Sumatera Selatan (Untuk mendukung program lumbung pangan nasional). Jurnal Teknik ITS, l(1), 2301-9271.

Widjaja-Adhi, I.P.G., Nugroho, K., Suriadikarta, D.A., dan Karama, A.S. (1992). Sumberdaya lahan rawa: potensi, keterbatasan dan pemanfaatan. Dalam Partohardjono, S., dan Syam, M. (Eds). Risalah Pertemuan Nasional Pengembangan Pertanian di Lahan Pasang Surut dan Lebak (pp 19-38), Bogor : Pusat Penelitian dan Pengembangan Pertanian.

Wijaya, T., Istianto, Susetyo, I., dan Ahmad, S.R. (2014). Teknologi pemupukan dan kultur teknis yang adaptif terhadap anomali iklim pada tanaman karet. Seminar Nasional Upaya Peningkatan Produktivitas Perkebunan dengan Teknologi Pemupukan dan Antisipasi Anomali Iklim, Jakarta, Maret 2014. 
Wijaya, T. dan Hidayati, U. (2003). Evaluasi lahan untuk pengembangan tanaman karet di Kabupaten Ogan Komering Ulu, Sumatera Selatan. Jurnal Penelitian Karet, 21(1-3), 1-11.
Wijaya, T., Rosyid, M.J., Sudiharto, dan Lasminingsih, M. (2009). Adaptasi klon dan tindakan kultur teknis untuk penanaman karet di lahan suboptimal. Prosiding Lokakarya Nasional Pemuliaan Tanaman Karet, Batam, Agustus 2009. 